\title{
Altered NMDA Glutamate Receptor Antagonist Response in Recovering Ethanol-Dependent Patients
}

\author{
John H Krystal*, 1,2,3, Ismene L Petrakis ${ }^{1,2,3}$, Diana Limoncelli, ${ }^{1,2}$, Elizabeth Webb ${ }^{1,2}$, Ralitza Gueorgueva ${ }^{2,3}$, \\ D Cyril D'Souza ${ }^{1,2,3}$, Nashaat N Boutros ${ }^{1,2,3}$, Louis Trevisan ${ }^{1,2,3}$, Dennis S Charney ${ }^{1,2,3,4}$ \\ 'Department of Veterans Affairs Alcohol Research Center, VA Connecticut Healthcare System (I l 6-A), West Haven, CT, USA; ${ }^{2}$ NIAAA Center for \\ the Translational Neuroscience of Alcoholism, Department of Psychiatry, Yale University School of Medicine, New Haven, CT, USA; ${ }^{3}$ Clinical \\ Neuroscience Research Unit, Abraham Ribicoff Research Facilities, New Haven, CT, USA; ${ }^{4}$ Mood and Anxiety Disorders Program, Intramural \\ Research Program, National Institute of Mental Health, Bethesda, MD, USA
}

\begin{abstract}
Ethanol is an antagonist of the N-methyl-D-aspartate (NMDA) glutamate receptor. Ethanol dependence upregulates NMDA receptors and contributes to crosstolerance with selective NMDA receptor antagonists in animals. This study evaluated whether recovering ethanol-dependent patients show evidence of a reduced level of response to the effects of the NMDA receptor antagonist, ketamine. In this double-blind study, 34 recently detoxified alcohol-dependent patients and 26 healthy comparison subjects completed 3 test days involving a 40-min infusion of saline, ketamine $0.1 \mathrm{mg} / \mathrm{kg}$, or ketamine $0.5 \mathrm{mg} / \mathrm{kg}$ in a randomized order. Recovering ethanol-dependent patients showed reduced perceptual alterations, dysphoric mood, and impairments in executive cognitive functions during ketamine infusion relative to the healthy comparison group. No attenuation of ketamine-induced amnestic effects, euphoria, or activation was observed. The alterations in NMDA receptor function observed in recovering ethanol-dependent patients may have important implications for ethanol tolerance, ethanol dependence, and the treatment of alcoholism.

Neuropsychopharmacology (2003) 28, 2020-2028, advance online publication, 23 July 2003; doi:I0.1038/sj.npp. 1300252
\end{abstract}

Keywords: ethanol; ethanol dependence; tolerance; reward; alcoholism; glutamate; N-methyl-D-aspartate (NMDA); executive cognitive function; psychosis

\section{INTRODUCTION}

The capacity of ethanol to block $N$-methyl-D-aspartate (NMDA) glutamate receptors is among its most potent actions in the brain (Krystal and Tabakoff, 2002). As a result, ethanol and more selective NMDA receptor antagonists share many physiologic, behavioral, and rewardrelated effects (Crews et al, 1996; Grant and Lovinger 1995). In animals (Grant and Colombo, 1993) and in humans (Krystal et al, 1998a), ethanol and other NMDA receptor antagonists show a dose-related similarity in their subjective effects.

Chronic ethanol administration upregulates NMDA receptor function. Sustained or chronic administration of ethanol and other NMDA receptor antagonists increases the mRNA or protein levels of some NMDA receptor subunits and the density of ligand binding to NMDA receptors in

*Correspondence: Dr JH Krystal, Psychiatry Service (II6-A), VA Connecticut Healthcare System, 950 Campbell Ave., West Haven, CT 065 16, USA, Tel: + I 203937 4790, Fax: + I 2039373468 ,

E-mail: john.krystal@yale.edu

Received 26 November 2002; revised 03 February 2003; accepted 18 February 2003

Online publication: 27 June 2003 at http://www.acnp.org/citations/ Npp052702432/default.pdf rodents and in cell lines (Darstein et al, 2000; Follesa and Ticku, 1996a, b; Gulya et al, 1991; Hu et al, 1996; Hu and Ticku 1995; Kalluri et al, 1998; Snell et al, 1996, 1993; Trevisan et al, 1994). In post-mortem studies, NMDA receptor upregulation is associated with human ethanol dependence (Freund and Anderson, 1996; Michaelis et al, 1993). Preclinical studies suggest that this NMDA receptor upregulation contributes to ethanol tolerance and the complications of ethanol withdrawal, including seizures and neurotoxicity (Crews et al, 1999; Hoffman et al, 1990; Thomas and Morrisett, 2000; Tsai et al, 1998).

This study examined whether recovering ethanol-dependent patients exhibited alterations in their responses to an NMDA receptor antagonist that might reflect alterations in NMDA receptor function. This objective was evaluated by comparing the dose-related effects of the NMDA receptor antagonist, ketamine, in patients and healthy comparison subjects.

\section{SUBJECTS AND METHODS}

\section{Patients}

Patients who met diagnostic criteria for ethanol dependence as determined by the Structured Clinical Interview for DSM- 
Table I Demographic Information on Subjects Participating in this Study

\begin{tabular}{|c|c|c|c|c|}
\hline & \multirow[b]{2}{*}{$\begin{array}{l}\text { Healthy } \\
\text { subjects }\end{array}$} & \multicolumn{3}{|c|}{ Ethanol-dependent patients } \\
\hline & & $\begin{array}{c}\text { Family history } \\
\text { positive }\end{array}$ & $\begin{array}{c}\text { Family history } \\
\text { negative }\end{array}$ & $\begin{array}{l}\text { Total alcoholic } \\
\text { subjects }\end{array}$ \\
\hline Males & 19 & 23 & 9 & 32 \\
\hline Females & 7 & 2 & 0 & 2 \\
\hline \multicolumn{5}{|l|}{ Ethnicity } \\
\hline Caucasian (\%) & 84.6 & 76 & 77 & 76.5 \\
\hline Hispanic (\%) & 3.8 & 12 & 11 & 11.8 \\
\hline African American (\%) & 3.8 & 8 & 11 & 8.8 \\
\hline Other (\%) & 7.8 & 4 & & 2.9 \\
\hline Age (years) & $29.1 \pm 9$ & $43.0 \pm 8.5$ & $45.9 \pm 11.9$ & $43.8 \pm 9.4$ \\
\hline Weight $(\mathrm{kg})$ & $78.4 \pm 15.9$ & $74.6 \pm 10.6$ & $77.1 \pm 9.2$ & $75.5 \pm 10.3$ \\
\hline Age first began drinking & & $15.8 \pm 3.3$ & $16.9 \pm 2.8$ & $16.1 \pm 3.2$ \\
\hline Age regular drinking & & $18.5 \pm 6.1$ & $19.9 \pm 6.9$ & $18.9 \pm 6.2$ \\
\hline Age of heaviest drinking & & $32.0 \pm 11.3$ & $35.0 \pm 13.8$ & $32.8 \pm 11.9$ \\
\hline Years of dependence & & $27.2 \pm 7.9$ & $29.0 \pm 10.3$ & $27.7 \pm 8.5$ \\
\hline Number of detoxifications & & $4.8 \pm 7.2$ & $8.7 \pm 13.9$ & $5.8 \pm 9.4$ \\
\hline $\begin{array}{l}\text { Milliliters of absolute alcohol } \\
\text { per day in month prior to } \\
\text { abstinence }\end{array}$ & & $358.1 \pm 239.6$ & $382.3 \pm 167.3$ & $364.5 \pm 220.6$ \\
\hline
\end{tabular}

III-R participated in testing (Spitzer et al, 1992). The characteristics of this patient group are presented in Table 1. The mean period of sobriety prior to testing was $18.4 \pm 4.8$ days. The mean \pm SD Michigan Alcoholism Screening Test score (Selzer, 1971) was $38.7 \pm 6.5$. Of the 34 patients in this study, $24(71 \%)$ met the von Knorring et al (1985) criteria for type 2 alcoholism, defined as age of onset before 25 years of age and two or more social consequences of alcoholism. Of the 34 patients, $25(73.5 \%)$ had a first-degree relative with a history of alcohol dependence determined by history (as per Addiction Severity Index). Patients were medically stable at study entry based on medical history, physical examination, and routine laboratory testing. Patients were excluded if they met criteria for substance use disorder other than nicotine dependence in the year prior to testing. In all, 19 patients (56\%) reported lifetime marijuana use, but only three subjects had used marijuana in the year prior to testing; 11 patients $(32 \%)$ had lifetime cocaine use. Of these patients, none used cocaine 6 months prior to testing at a subabuse level and the remainder had not used cocaine for at least 1 year prior to testing. Cigarette smoking data were available on 22 of the patients. Of the 22 patients, 17 were habitual smokers. The absence of other current substance abuse was supported by negative results of urine toxicological screens prior to testing. Subjects were also excluded if they had another DSM-III-R Axis I diagnosis during a period that was free of alcohol consumption.

Patients were in-patients at the Substance Abuse Treatment Research Unit of the Veterans Affairs Connecticut Healthcare System, West Haven Campus. They received clinical care as in-patients for the duration of the study and their in-patient treatment was not contingent upon their participation in this study. Following participation in this study and completion of in-patient treatment, patients were followed as outpatients in the VA Substance Abuse Clinic. A total of 20 patients completed detoxification with pharmacologic supports prior to study entry (benzodiazepines, $n=16$; nimodipine, $n=4$ ). The mean \pm SD period between the administration of the last benzodiazepine dose and the first pharmacologic test day was $14.6 \pm 5.3$ days (range, 521 days). In all, 59 patients signed consent forms. From this group, 34 patients completed 3 test days, four patients completed 2 test days (three patients terminated their inpatient treatment and were disqualified from further participation following the administration of ketamine $0.1 \mathrm{mg} / \mathrm{kg}$ (low dose ketamine), and one patient was excluded due to hypertension), three patients completed 1 test day (one patient received placebo, one patient received ketamine $0.1 \mathrm{mg} / \mathrm{kg}$, and one patient received ketamine $0.5 \mathrm{mg} / \mathrm{kg}$; all three patients terminated their in-patient treatments), and 18 patients did not participate in any test days. On their first test day, patients received placebo $(n=11), 0.1 \mathrm{mg} / \mathrm{kg}$ ketamine hydrochloride $(n=13)$ or $0.5 \mathrm{mg} / \mathrm{kg}$ ketamine hydrochloride $(n=10)$. No serious adverse events were attributable to ketamine infusion in this study.

A previous report described the specificity of behavioral and neuroendocrine responses in a subgroup $(n=20)$ of the patients in this study (Krystal et al, 1998a), but it did not include most of the outcome measures reported here and it did not include a comparison of patients to healthy subjects.

\section{Healthy Subjects}

Comparison subjects were recruited by public advertisement and were compensated for their participation. They were selected after a brief structured interview that excluded individuals with a lifetime history of a DSM-III-R axis I diagnosis (Spitzer et al, 1990), history of consultation for an emotional difficulty, or psychiatric illness or alcoholism in a first-degree relative. Subjects were free of substance use disorder, other than nicotine dependence, as confirmed by urine toxicology results at the initial screening and on test days. Two of the 26 healthy subjects were habitual smokers. Subjects refrained from consuming psychoactive substances, including caffeine-containing foods or beverages for 2 weeks before testing and during the 2 weeks of testing. 
Subjects were free of medical illness as indicated by a medical history review, physical examination, and results of routine laboratory tests. A total of 36 subjects signed consent forms. In all, 26 subjects completed 3 test days (see Table 1 for demographic data), two subjects completed 2 test days (both subjects terminated their participation after receiving ketamine $0.5 \mathrm{mg} / \mathrm{kg}$ after finding the effects unpleasant), two subjects completed 1 test day (one subject was terminated due to eosinophilia and one subject was excluded from further participation after ketamine infusion was terminated due to a pronounced but transient emotional reaction), and six subjects did not participate in any testing. Despite the termination of ketamine infusion due to a strong ketamine reaction in one subject, no serious adverse events attributable to ketamine infusion occurred in this study. Data from a subgroup $(n=18)$ of the comparison subjects appeared in a prior report (Krystal et al, 1994).

\section{Testing Procedure}

This research protocol was approved by the Human Subjects Subcommittee of the Veterans Affairs Connecticut Healthcare System (West Haven, CT) and the Human Investigations Committee of the Yale University School of Medicine (New Haven, CT). After giving informed consent, each subject completed 3 test days separated by 3-7 days in a randomized order under double-blind conditions. The consent form included a warning that the effects of ketamine might resemble ethanol intoxication and might stimulate craving for alcohol. On each test day, patients received a 40-min intravenous infusion of saline solution, $0.1 \mathrm{mg} / \mathrm{kg}$ ketamine hydrochloride, or $0.5 \mathrm{mg} / \mathrm{kg}$ ketamine hydrochloride (Ketalar, Parke-Davis, Kalamazoo, MI). This method of administration was similar to that reported previously in healthy subjects and ethanol-dependent patients (Krystal et al, 1994, 1998b). Prior to testing, participants fasted overnight and they remained in a fasting state during the test session. They presented for testing at approximately 0830 and an intravenous line was placed at that time.

Psychosis, negative symptoms, mood, and behavior changes were assessed using the Brief Psychiatric Rating Scale (BPRS) (Krystal et al, 1994; Hedlund and Vieweg 1980; Overall and Gorham 1962). Using the BPRS, psychosis (conceptual disorganization, hallucinatory behavior, suspiciousness, and unusual thought content), negative symptoms (blunted affect, emotional withdrawal, and motor retardation), psychomotor activation (tension, mannerisms, and posturing, excitement), and dysphoric mood (anxiousdepression factors: anxiety, guilt feelings, depressive mood, somatic concern, tension, and motor retardation) were assessed. The BPRS was administered 30 and $15 \mathrm{~min}$ prior to infusion and at the 20-, 80-, 110-, and 230-min postinfusion timepoints.

Learning and memory were assessed using an item from the Mini-Mental State Examination (MMSE) (Folstein et al, 1975). This study slightly modified this examination to add an assessment of word recall following a 10-min delay. For the memory assessment, separate sets of words, selected on the basis of their comparable frequency of use in the English language and comparable difficulty (Kucera and Francis, 1967), were presented at each time point. Thus, each set of words was presented once, but recall was assessed three times: (1) immediately following presentation, (2) following a distracting task, and (3) following a 10-min delay. The MMSE, including memory testing, was presented $85 \mathrm{~min}$ before ketamine infusion and at the 10-, 80-, 110-, and 230min timepoints. Vigilance to visual stimuli was measured by using a continuous performance task (CPT) (Gordon, 1983) in which subjects attended to numbers that were presented sequentially on a screen. The subject pushed a button to signal when a ' 9 ' was preceded by a ' 1 '. This study also employed a computerized version of the Wisconsin Card Sorting Test (WCST) (developed and validated by Donald Quinlan, PhD, unpublished data, September 1990). The CPT and WCST were administered consecutively once per test day beginning $20 \mathrm{~min}$ after the start of the ketamine infusion.

Patients and healthy subjects completed visual analog scales (VASs) of high and drowsiness. These scales were completed at 30 and 15 min prior to ketamine infusion and $10,40,80,110,170$, and $230 \mathrm{~min}$ after the initiation of ketamine infusion.

\section{Data Analysis}

Except when noted, data in this study were analyzed as ordinal data because the data were not normally distributed and they were not easily fit to alternative models. Analyses were performed using SAS Version 8.2. Cumulative logit GEE models (Miller et al, 1993) for ordinal data and these models were applied using PROC GENMOD for the analysis of the BPRS and VAS data. For the reported BPRS subscales and VAS scales, data were categorized as described in the Results section. Group, dose, and time effects, all possible interactions of these main effects, and age effects were considered as predictors. Independence working correlation matrix was assumed. The analysis was restricted to dose and time levels for which there was variability in the data. For most outcome measures, there was no variability at baseline and in the placebo group, that is, most subjects had the equivalent of a ' 0 ' score at all timepoints. When the age effect and higher order interactions involving the group and dose and time effects were not significant, they were dropped from the model for parsimony. Estimates of log odds ratios and $95 \%$ confidence intervals were computed for the significant effects in the reduced models. The vital signs data were assessed for normality prior to analysis using normal probability plots and the Shapiro-Wilks test statistic. These data were analyzed using a mixed model with fixed effects of group, dose, and time and all possible interactions of these factors as well as a random subject effect in SAS PROC MIXED (Brown and Prescott, 1999). The correlation structure within each individual was modeled with a random subject effect and structured variancecovariance matrix within day within subject. The best fitting correlation structure was selected according to Akaike Information Criterion and Schwartz Bayesian criterion.

The WCST perseverative errors data were log-transformed to achieve normality and analyzed using a linear regression model with group, dose, and age and all possible interactions as predictors. Backwards selection using $\alpha=0.05$ was used to drop insignificant effects from the model one at a time. The ordinal outcome number of 
criteria met was analyzed using the CATMOD procedure in SAS with mean response function. The number of trials for completing the first category was analyzed by estimating survival curves for each group by dose combination and comparing the survival curves using the log-rank test in SAS PROC LIFETEST. Cox proportional hazards model was also fitted within the PHREG procedure after checking the proportional hazards assumption (Grambsch and Therneau, 1994). Four subjects failed to complete even one category and hence were treated as censored with number of trials equal to the maximum possible (128). Unlike usual survival analysis in this analysis, a better outcome is a smaller number of trials to completion of first category.

The $A^{\prime}$ measure in the Gordon box data was analyzed using a GEE model (Liang and Zeger, 1986) with gamma response, log link function, and compound symmetry working correlation structure. The model included fixed effects for dose, group, and dose by group interaction. Age was used as a covariate, but since it was not significant it was dropped from the final model. The postrecall and delayed recall measurements of the mini-mental data were analyzed using a cumulative-logit GEE model. All but two of the immediate recall measurements were equal to the maximum possible number of three words and hence were not included in the analysis. Group, dose, time and type of recall (post $v s$ delayed), all possible interactions of these factors and age were included in the model. Backwards selection was used to drop insignificant effects at 0.05 level one at a time for parsimony. The effects of patient age, age of onset of alcoholism, duration of alcohol use, number of detoxifications, family history of alcoholism, and alcohol consumed in previous month on all outcome variables for alcoholics were assessed by adding these factors one at a time to the models described above with the group factor omitted.

In all post hoc analyses, Bonferroni corrections were applied to adjust the level of significance for multiple comparisons.

\section{RESULTS}

\section{Behavioral and Subjective Responses}

BPRS psychosis. As described in Figure 1, ethanoldependent patients had a markedly blunted psychotic response to ketamine relative to healthy subjects. In the analysis of the four key positive symptom scores, scores were first clustered into low (scores: 4-6), medium (scores: $7-9$ ), or high scores (scores: $\geqslant 10$ ) for analysis in a cumulative logit GEE model. These clusters were created following examination of the data to insure an adequate amount of data in each component. However, in both groups receiving placebo and the ketamine $0.1 \mathrm{mg} / \mathrm{kg}$ dose, all the subjects exhibited low scores, that is, there were no medium or high scores. As a result, it was necessary to limit the analysis to the ketamine $0.5 \mathrm{mg} / \mathrm{kg}$ dose. Within the ketamine $0.5 \mathrm{mg} / \mathrm{kg}$ test day, medium and high responses were limited to the assessment made 20 min following the initiation of ketamine infusion. Therefore, a cumulative logit model that included diagnosis and age as predictors was fitted. The age effect was not significant and it was dropped from the model. The effect of diagnosis was

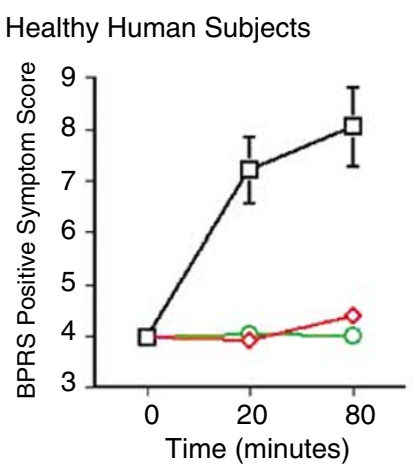

Ethanol Dependent Patients

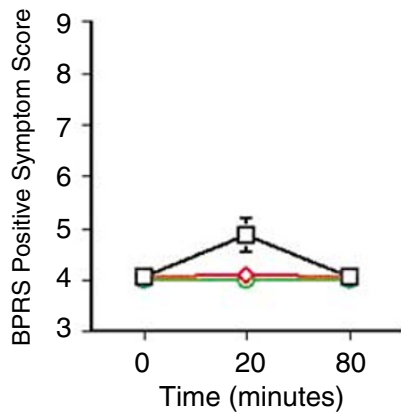

Figure I The effects of placebo (circles), ketamine $0.1 \mathrm{mg} / \mathrm{kg}$ (diamonds), and ketamine $0.5 \mathrm{mg} / \mathrm{kg}$ (squares) on the BPRS four key positive symptom scores in healthy human subjects $(n=26$; left figure) and recovering ethanol-dependent patients $(n=34$; right figure). Values are presented as mean \pm standard error of the mean (SEM). See 'Patients and methods' and 'Results' sections for explanation of statistical analyses.
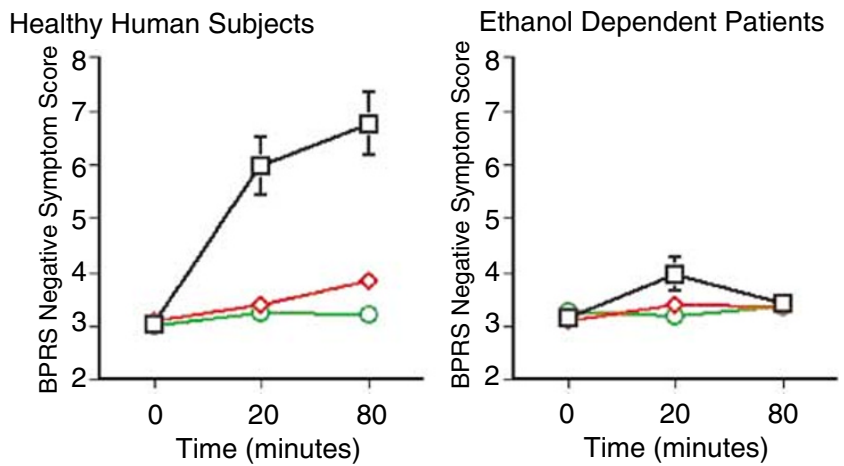

Figure 2 The effects of placebo (circles), ketamine $0.1 \mathrm{mg} / \mathrm{kg}$ (diamonds), and ketamine $0.5 \mathrm{mg} / \mathrm{kg}$ (squares) on the BPRS three key negative symptom scores in healthy human subjects $(n=26$; left figure) and recovering ethanol-dependent patients ( $n=34$; right figure). Values are presented as mean \pm SEM. See 'Patients and Methods' and 'Results' sections for explanation of statistical analyses.

significant $\left(\chi^{2}(1)=10.86, P=0.001\right)$, with healthy subjects having greater odds of a more pronounced response than patients (odds ratio $=12.84,95 \%$ CI: $2.81,58.58$ ). The presence of a family history of ethanol dependence, the age of onset of ethanol dependence, the number of ethanol detoxifications, and the duration of ethanol dependence did not influence the psychotic response to ketamine in the patient group.

BPRS negative symptoms. Patients were also blunted in the display of ketamine-induced blunting of affect, withdrawal, and psychomotor retardation, as seen in Figure 2. In the analysis of these three key negative symptom scores, scores were first clustered into low (scores: $3-5$ ), medium (scores: $6-8$ ), or high scores (scores: $\geqslant 9$ ) for analysis in a cumulative logit GEE model. In this model, a significant effect of ketamine dose $\left(\chi^{2}(2)=17.25, P=0.0002\right)$ and significant diagnosis by ketamine dose $\left(\chi^{2}(2)=12.84\right.$, $P=0.0016)$ and group by time $\left(\chi^{2}(2)=3.81, P=0.05\right)$ were observed. At the ketamine $0.5 \mathrm{mg} / \mathrm{kg}$ dose, healthy subjects had substantially greater likelihood of a medium-to-high score than did patients (odds ratio $=19.27,95 \%$ CI: 6.40 , 
57.98), while the groups did not differ at the low dose and placebo dose of ketamine. In a secondary analysis where alcoholism-related characteristics were added as covariates, none of the effects were significant. However, there were associations whose statistical significance did not survive Bonferroni correction, for the number of ethanol detoxifications and the absence of a family history of ethanol dependence to be associated with greater ketamine responses.

BPRS dysphoric mood. Ketamine produced a more pronounced dysphoric mood response in healthy subjects than it did in patients, as measured by the BPRS anxiousdepression factor (Figure 3 ). In the analysis of these three key negative symptom scores, scores were first clustered into low (scores: 6-7), medium (scores: 8-10), or high scores (scores: $\geqslant 11$ ) for analysis in a cumulative logit GEE model. The anxious-depression factor was the only BPRS factor where there was significant baseline variability across test days, therefore baseline scores were added to the cumulative logit GEE model as a covariate. Also, the analysis was restricted to the 20- and 80-min timepoints as these were the only timepoints where medium and high scores were observed. The analysis revealed a significant group by dose by time interaction $\left(\chi^{2}(2)=7.31, P=0.026\right)$, with healthy subjects exhibiting significantly greater responses at the $80-\mathrm{min}$ (odds ratio $=26.46,95 \% \mathrm{CI}: 6.6$, 106.1) timepoint. None of the alcoholism-related characteristics was significantly associated with ketamine response after Bonferroni correction.

BPRS activation. Ketamine produced a dose-related activating effect in both groups $\left(\chi^{2}(2)=14.15, P=0.0008\right)$. However, unlike other BPRS factors, there were no significant group differences. Characteristics of ethanol dependence did not modify this dimension of ketamine response in the patient group.

VAS assessing euphoria ('high'). Although ketamine produced significant euphoria at the $0.5 \mathrm{mg} / \mathrm{kg}$ dose $\left(\chi^{2}(1)=91.35, P<0.0001\right)$ in both groups, no group-related differences were significant in the analysis (see Figure 4).

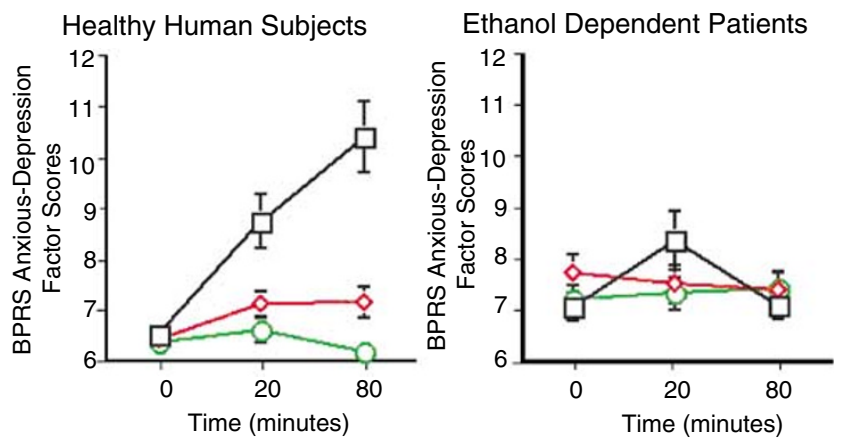

Figure 3 The effects of placebo (circles), ketamine $0.1 \mathrm{mg} / \mathrm{kg}$ (diamonds), and ketamine $0.5 \mathrm{mg} / \mathrm{kg}$ (squares) on the BPRS anxious-depression factor scores in healthy human subjects ( $n=26$; left figure) and recovering ethanol-dependent patients ( $n=34$; right figure). Values are presented as mean \pm SEM. See 'Patients and Methods' and 'Results' sections for explanation of statistical analyses.
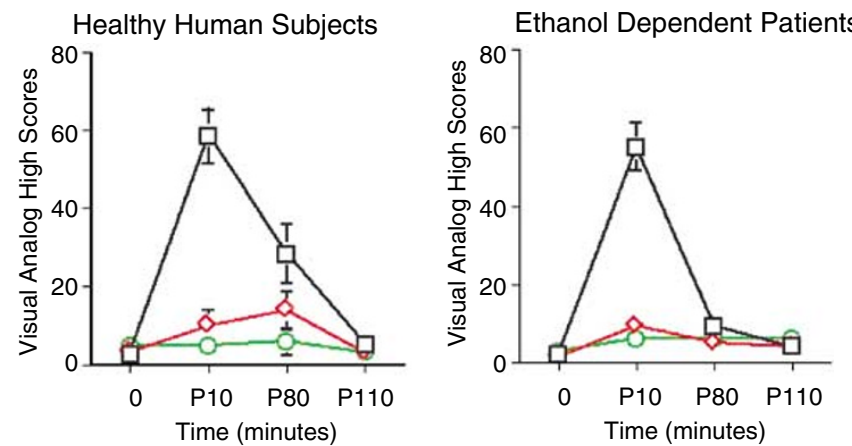

Figure 4 The effects of placebo (circles), ketamine $0.1 \mathrm{mg} / \mathrm{kg}$ (diamonds), and ketamine $0.5 \mathrm{mg} / \mathrm{kg}$ (squares) on the 'high' VAS scores in healthy human subjects ( $n=26$; left figure) and recovering ethanoldependent patients ( $n=34$; right figure). Values are presented as mean \pm SEM. See 'Patients and Methods' and 'Results' sections for explanation of statistical analyses.

VAS assessing drowsiness. Although ketamine produced significant sedation at the $0.5 \mathrm{mg} / \mathrm{kg}$ dose $\left(\chi^{2}(1)=19.05\right.$, $P=0.0003)$ in both groups, no group-related differences were significant in this analysis.

\section{Measures of Cognitive Function}

CPT of vigilance. No diagnosis effects were evident in the analysis of CPT data for discriminability $\left(A^{\prime}\right)$ as defined previously (Nestor et al, 1991, 1990). Data were analyzed using a GEE model with gamma response, log link function and compound symmetry working correlation structure. Analysis of placebo day data from the patient group indicated that advancing age $\left(\chi^{2}(1)=8.94, P<0.003\right)$ and number of detoxifications $\left(\chi^{2}(1)=19.80, P<0.0001\right)$ were associated with reduced vigilance, as reflected in lower $A^{\prime}$ scores. Within the patient group, the following effects were associated with greater attention impairment, lower $A^{\prime}$ scores, with increasing ketamine dose: earlier age of ethanol dependence onset $\left(\chi^{2}(2)=15.43, P=0.0004\right)$ and increased duration of ethanol use $\left(\chi^{2}(2)=35.55, P<0.0001\right)$.

Learning and memory. Diagnosis, ketamine dose, the duration of the delay between stimulus presentation and testing, and the order of the test days influenced performance on this measure. As previously reported in healthy subjects (Krystal et al, 1994), nearly all subjects performed perfectly on immediate recall (three of three items correct), regardless of diagnosis or ketamine dose. Thus, there was very little variance in this outcome for further analysis of this outcome measure. The patient group had reduced recall scores relative to the comparison subjects $\left(\chi^{2}(1)=19.04, P<0.0001\right)$, but none of the interactions of diagnosis and other main effects reached significance. Across groups, the higher dose of ketamine produced a greater impairment in recall as the delay between stimulus presentation and testing increased from the postdistraction timepoint to a 10 -min delay (ketamine dose by delay by time: $\left.\chi^{2}(8)=16.91, P=0.03\right)$. In this analysis, age was not related to recall scores. With regard to test day order, the day by group interaction effect was significant $\left(\chi^{2}(2,12.62)=0.0018\right)$, but the day effect was not significant $\left(\chi^{2}(2)=4.51, P=0.10\right)$. The healthy subjects 
improved significantly from day 1 to day $3\left(\chi^{2}(1)=7.61\right.$, $P=0.0058$ ) even though they were presented with novel word lists every time this test was administered, while the patients did not significantly improve between day 1 and day $3\left(\chi^{2}(1)=0.82, P=0.37\right)$. Interactions of test day order with ketamine dose were significant. For the patient group, a cumulative-logit model was fitted for the placebo day and for delayed recall on the ketamine $0.5 \mathrm{mg} / \mathrm{kg}$ test day, covarying for the postdistraction recall scores. The only alcoholism variable that influenced delayed recall score was family history of ethanol dependence. On the placebo day, patients with a family history of ethanol dependence had better delayed recall scores $(\mathrm{OR}=0.5,95 \% \mathrm{CI}=(0.26,0.96)$; $\left.\chi^{2}(1)=4.34, P=0.04\right)$, while patients without a family history of ethanol dependence had superior delayed recall scores following the administration of ketamine $(\mathrm{OR}=4.0$, $\left.95 \% \mathrm{CI}=(1.66,9.67) ; \chi^{2}(1)=9.54, P=0.002\right)$. To simplify the presentation of the memory data, the results for the lowest score on each test day for each type of recall and for each group are presented in Figure 5.

Wisconsin Card Sorting Test. For the sake of brevity, three WCST outcomes are reported here: perseverative errors, the number of matching criteria met, and the number of trials to first criteria (Figure 6). For these outcomes, only the data from the first test day were analyzed. For perseverative errors, analysis using a mixed regression model revealed a significant interactive effect of diagnosis and ketamine dose, controlling for age $(\mathrm{F}(2,62)=5.8, P=0.005)$. The overall pattern was that patients made more perseverative errors than healthy subjects on the placebo $(F(1,62)=9.02$, $P=0.003)$ and ketamine $0.1 \mathrm{mg} / \mathrm{kg}$ test days $(\mathrm{F}(1,62)=5.18, P=0.026)$, but the groups did not differ on the ketamine $0.5 \mathrm{mg} / \mathrm{kg}$ test day. Healthy subjects $(\mathrm{F}(2,62)=11.1, P<0.0001)$, but not patients, significantly increased their perseverative errors as ketamine dose increased. Among the patients, the number of perseverative
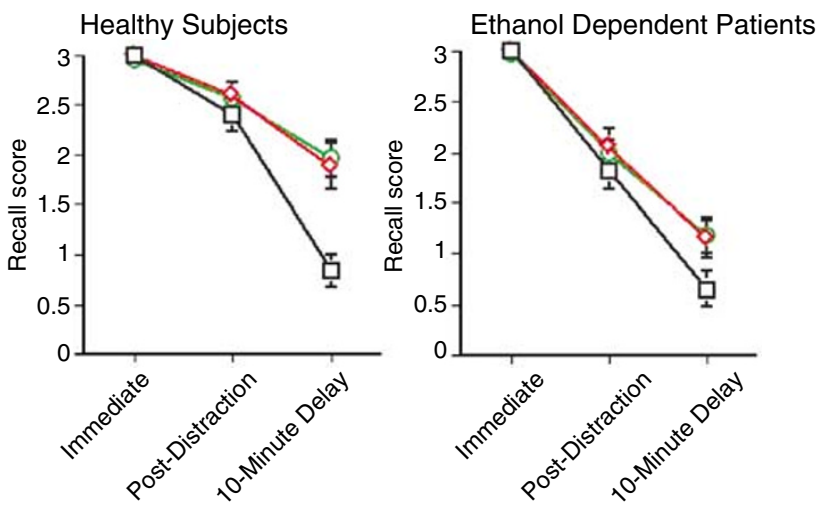

Figure 5 The dose-related effects of ketamine upon the lowest score achieved on each test day for immediate recall, postdistraction recall, and delayed (I0-min) recall for the memory item of the MMSE. Values are presented as mean \pm SEM for healthy human subjects ( $n=26$; left figure) and recovering ethanol-dependent patients $(n=34$; right figure). Statistical methods are described in the text. Significant diagnosis $\left(\chi^{2}(1)=15.9\right.$, $P<0.0001$ ), ketamine dose $\left(\chi^{2}(2)=17.6, P=0.0002\right)$, delay $\left(\chi^{2}(1)=65.1\right.$, $P<0.000 \mathrm{I})$, and ketamine dose by delay interaction $\left(\chi^{2}(2)=15.1\right.$, $P=0.0005)$ effects were observed. $* P<0.000$ I for comparisons with the ketamine $0.5 \mathrm{mg} / \mathrm{kg}$ test day.
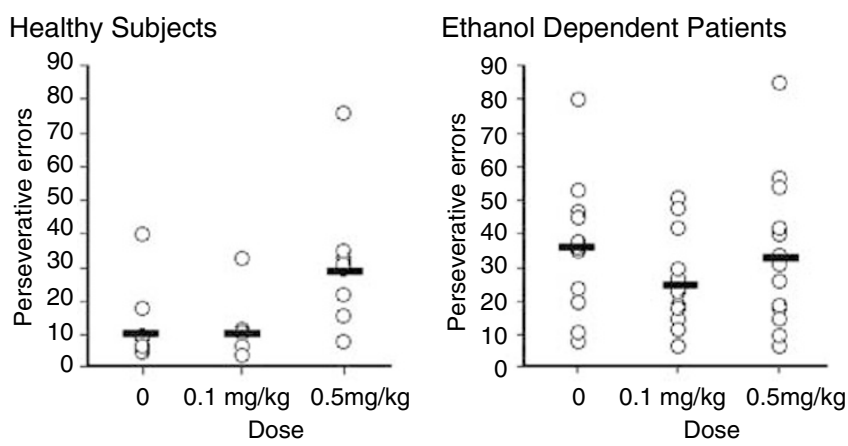

Figure 6 The dose-related effects of ketamine upon the number of perseverative errors made during the first attempt at completion of the WCST in healthy human subjects $(n=26$, left figure) and recovering ethanol-dependent patients ( $n=34$, right figure). Individual subjects are represented as circles and the mean for each group is presented as a black line. See 'Patients and Methods' and 'Results' sections for explanation of statistical analyses.
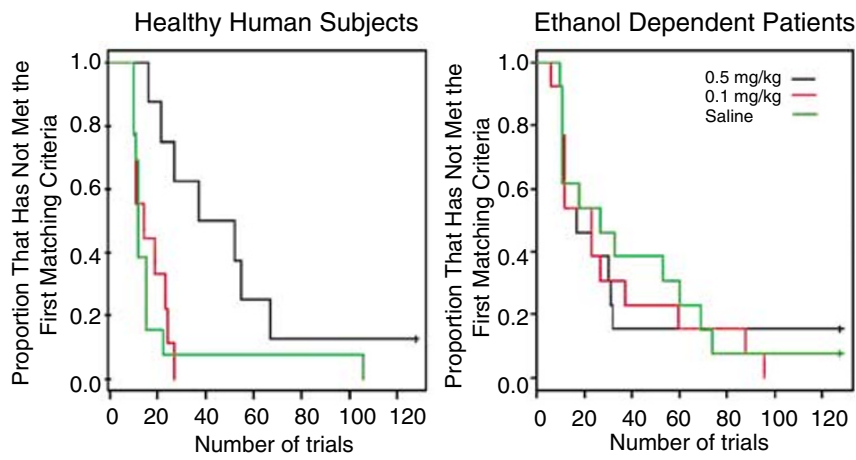

Figure 7 A lifetable graph of the dose-related effects of ketamine upon the number of trials that it takes to meet the first matching criteria on the WCST in healthy human subjects $(n=26$, left figure) and recovering ethanol-dependent patients ( $n=34$, right figure). The $y$-axis of each graph depicts the proportion of each group that has not met the matching criteria and the $x$-axis presents the number of trials attempted by each group. Thus, impaired performance on this aspect of the WCST in these figures is reflected in a more shallow rate of decline in the proportion of each group that has not met the first matching criteria. See 'Patients and Methods' and 'Results' sections for explanation of statistical analyses.

errors was positively correlated with the duration of ethanol dependence (Pearson $r=0.43, P=0.007$ ).

The number of trials needed for the successful completion of the first matching criterion on the WCST also exhibited a diagnosis by ketamine dose interaction (Figure 7). These data were analyzed by estimating survival curves for each of six subgroups defined by their diagnosis and the agent that they received on their first test day. Cox proportional hazards model were fitted to compare the six categories. The LIFETEST and PHREG procedures in SAS were used. Four subjects failed to complete even one category and hence were assigned the maximum possible number of trials (128). The Cox proportional hazards model showed that ketamine $0.5 \mathrm{mg} / \mathrm{kg}$ significantly increased the number of trials to the first criteria in healthy comparison subjects relative to placebo $\left(\chi^{2}(1)=0.006\right)$, and ketamine $0.1 \mathrm{mg} / \mathrm{kg}$ $\left(\chi^{2}(1)=0.002\right)$ for controls. Ketamine did not have significant effects in patients. 
The number of criteria met was analyzed using CATMOD procedure. Significant effects of diagnosis $\left(\chi^{2}(1)=27.9\right.$, $P<0.0001)$ and ketamine dose $\left(\chi^{2}(2)=7.8, P=0.02\right)$ were observed, but the group by ketamine dose interaction did not reach significance. There was a nonsignificant negative correlation between the number of detoxifications and the number of criteria met among patients (Spearman's $r=-0.63)$; all other correlations were smaller in magnitude.

\section{Physiologic Responses}

Relative to the comparison group, recovering ethanoldependent patients showed increased time-dependent systolic blood pressure responses (group by time: $\mathrm{F}(7,1112)=7.61, \quad P<0.0001$; ketamine dose by time: $\mathrm{F}(14,1112)=8.72, P<0.001)$, similar ketamine-induced increases in diastolic blood pressure (ketamine dose by time: $\mathrm{F}(7,1111)=8.07, P<0.0001)$, and reduced time-dependent increases in pulse (diagnosis by time: $F(7,1129)=5.59$, $P<0.0001)$.

\section{COMMENTARY}

The response to the NMDA glutamate receptor antagonist, ketamine, was markedly altered in recovering ethanoldependent patients compared to a healthy comparison group. Ketamine produced transient symptoms in healthy subjects including psychosis, negative symptoms, dysphoric mood, perceptual changes, impairment of vigilance and memory, disruption of WCST performance, and hypertension (Domino et al, 1965; Ghoneim et al, 1985; Krystal et al, 1994; Malhotra et al, 1996; Newcomer et al, 1999; Oye et al, 1992; Vollenweider et al, 1997). Relative to healthy subjects, following ketamine administration recovering ethanoldependent patients exhibited reduced psychosis, negative symptoms, dysphoric mood, and worsening of executive cognitive function, as measured by the WCST. Diagnosisrelated effects on ketamine response remained significant when controlling for the fact that the patient group was older and had mild baseline impairments of WCST performance. In contrast, the stimulatory and euphoric effects of ketamine, as measured by the BPRS activation factor and the 'high' VAS were not blunted in patients relative to the healthy subjects. However, a higher percentage of the patient group were habitual cigarette smokers compared to the healthy subjects. The distribution of smokers in each group, unfortunately, did not permit the evaluation of the impact of nicotine dependence upon the current findings.

The current results support the hypothesis that ethanoldependent patients exhibit tolerance to some effects of other NMDA receptor antagonists. This interpretation is consistent with preclinical studies suggesting that NMDA antagonists suppress ethanol withdrawal seizures (Grant et al, 1992) and produce tolerance to the cognitive effects of ethanol (Rafi-Tari et al, 1996). Tolerance to the effects of NMDA antagonists has been attributed to upregulation of NMDA receptors (Tsai and Coyle, 1998). Upregulation of NMDA receptors by chronic ethanol administration may contribute to the altered sensitivity to ketamine effects observed in patients in this study. However, preclinical
(Kalluri et al, 1998) and clinical (Freund and Anderson, 1996) studies suggest that increased NMDA receptor binding attributable to chronic ethanol administration is time-limited. Thus, ethanol-related NMDA receptor upregulation may play a greater role in acute rather than protracted withdrawal.

Patients in this study showed a shift in the balance of negative and positive effects of ketamine administration, that is, its reward valence. Dysphoric or negative ketamine effects, such as the psychosis, dysphoric mood, and impaired cognition, were attenuated in patients while the euphoric and stimulatory responses to ketamine were preserved. The mechanisms underlying this shift in the reward valence of ketamine effects are unknown, but may be related to factors that control regional changes in NMDA receptor function, including the status of NMDA receptors (density, subunit composition, phosphorylation status of receptor subunits, etc), NMDA receptor-related signal transduction, and voltage-gated or G-protein-gated ion channels (Krystal and Tabakoff, 2002). Altered NMDA antagonist responses could also reflect network consequences of alterations in NMDA receptor function, such as alterations in the release of glutamate and dopamine (Moghaddam et al, 1997). In particular, the changes in ketamine response observed in patients in this study are reminiscent of the impact of pretreatment with an antagonist of voltage-gated cation channels on ketamine response. Both lamotrigine and nimodipine reduce the dysphoric effects of ketamine and preserve or promote its euphoric effects in both healthy subjects (Anand et al, 2000) or recovering ethanol-dependent patients (Krupitsky et al, 2001). The effects of lamotrigine were thought to reflect, in part, its capacity to reduce the stimulatory effects of ketamine on glutamate release.

A potential limitation of the current study was its selection of ketamine as the NMDA receptor antagonist. This study employed the racemic ketamine mixture available currently in the United States, which has a number of lower affinity actions in addition to NMDA receptor antagonism (Hustveit et al, 1995). Thus, some of the findings could reflect altered responses to non-NMDA receptor-related actions of ketamine, including effects on dopamine or opiate receptors. In this regard, though, pretreatment with haloperidol $5 \mathrm{mg}$ (Krystal et al, 1999b) or naltrexone $25 \mathrm{mg}$ (J Krystal, unpublished data) could not block the euphoric effects of ketamine when administered to healthy humans at similar doses. Further, the involvement of NMDA receptors in the findings reported in this study is supported by two preliminary studies reporting altered responses to NMDA receptor antagonists with differing secondary sites of action (Krystal et al, 1999a; Schutz and Soyka, 2000). Yet, this study is limited by the absence of ketamine and norketamine blood levels. As a result, this study cannot rule out the possibility that differences in drug metabolism contributed to the current findings.

Lastly, this study found evidence that clinical features of the ethanol dependence history were related to the altered response to ketamine. Early age of ethanol dependence onset and duration of ethanol dependence were associated with greater impairment of attention and WCST performance by ketamine. These relationships may reflect both 
the detrimental consequences of long-term alcoholism upon brain structure and function as well as the possibility that early onset alcohol-dependent patients reflect a distinct neurobiological subtype from those patients with a later onset of illness.

In summary, this study reported profound alterations in the response to the NMDA receptor antagonist, ketamine, among patients recovering from ethanol dependence. Dysphoric responses to ketamine were reduced markedly while euphoric responses were enhanced. This protracted, perhaps permanent, shift in NMDA receptor antagonist response may have implications for the subsequent response of these patients to ethanol. NMDA antagonism comprises a key component of the action of ethanol in the brain. To the extent that the negative consequences of the ingestion of this NMDA antagonist are mitigated as a consequence of ethanol dependence, patients lose a potentially important negative feedback on their heavy drinking. Yet, they appear to experience the full euphoric effects of NMDA receptor antagonism. If a shift in the reward valence of NMDA antagonist effects occurs in the context of ethanol dependence that promotes heavy drinking, then novel treatments may be developed for alcoholism that 'correct' the alteration in NMDA receptor function or restore the normal reward valence of NMDA receptor antagonist effects.

\section{ACKNOWLEDGEMENTS}

This research was supported by Grants 1R01 AA10121-01, RO1 AA12308-01, KO2 AA 00261-01, and P50 AA12870-01 from the National Institute on Alcohol Abuse and Alcoholism (Bethesda, MD) (Drs Krystal, Petrakis), and the Department of Veterans Affairs (Washington, DC) through funding of the Department of Veterans Affairs Alcohol Research Center and a Merit Review Grant (Drs Krystal, Petrakis). We wish to acknowledge the critical contributions to this research made by the clinical and research staff of the Biostudies Unit and Substance Abuse Treatment Unit of the VA Connecticut Healthcare System (West Haven, CT). We also thank Robert Gibbons, PhD for his consultation to the data analysis plan.

\section{REFERENCES}

Anand A, Charney DS, Cappiello A, Berman RM, Oren DA et al (2000). Lamotrigine attenuates ketamine effects in humans: support for hyperglutamatergic effects of NMDA antagonists. Arch Gen Psychiatry 57: 270-276.

Brown H, Prescott R (1999). Applied Mixed Models in Medicine. John Wiley and Sons: New York.

Crews FT, Morrow AL, Criswell H, Breese G (1996). Effects of ethanol on ion channels. Int Rev Neurobiol 39: 283-367.

Crews FT, Waage HG, Wilkie MB, Lauder JM (1999). Ethanol pretreatment enhances NMDA excitotoxicity in biogenic amine neurons: protection by brain derived neurotrophic factor. Alcoholism: Clin Exp Res 23: 1834-1842.

Darstein MB, Landwehrmeyer GB, Feuerstein TJ (2000). Changes in NMDA receptor subunit gene expression in the rat brain following withdrawal from forced long-term ethanol intake. Naunyn-Schmiedebergs Arch Pharmacol 361: 206-213.
Domino EF, Chodoff P, Corssen G (1965). Pharmacologic effects of CI-581, a new dissociative anesthetic, in man. Clin Pharmacol Ther 6: 279-291.

Follesa P, Ticku MK (1996a). Chronic ethanol-mediated upregulation of the $N$-methyl-D-aspartate receptor polypeptide subunits in mouse cortical neurons in culture. J Biol Chem 271: 13297-13299.

Follesa P, Ticku MK (1996b). NMDA receptor upregulation: molecular studies in cultured mouse cortical neurons after chronic antagonist exposure. J Neurosci 16: 2172-2178.

Folstein MF, Folstein SE, McHugh PR (1975). Mini-mental state': a practical method of grading the cognitive state of patients for the clinician. J Psychiatr Res 12: 189.

Freund G, Anderson KJ (1996). Glutamate receptors in the frontal cortex of alcoholics. Alcoholism: Clin Exp Res 20: $1165-1172$.

Ghoneim MM, Hinrichs JV, Mewaldt SP, Petersen RC (1985). Ketamine: behavioral effects of subanesthetic doses. J Clin Psychopharmacol 5: 70-77.

Gordon M (1983). Gordon Diagnostic Systems. Gordon Systems: DeWitt, New York.

Grambsch PM, Therneau TM (1994). Proportional hazards tests and diagnostics based on weighted residuals. Biometrika 81: 515-526.

Grant KA, Colombo G (1993). Discriminative stimulus effects of ethanol: effect of training dose on the substitution of $N$-methylD-aspartate antagonists. J Pharmacol Exp Ther 264: 1241-1247.

Grant KA, Lovinger DM (1995). Cellular and behavioral neurobiology of alcohol: receptor-mediated neuronal processes. Clin Neurosci 3: 155-164.

Grant KA, Snell LD, Rogawski MA, Thurkauf A, Tabakoff B (1992). Comparison of the effects of the uncompetitive $N$-methyl-Daspartate antagonist (+-)-5-aminocarbonyl-10,11-dihydro-5Hdibenzo[a,d] cyclohepten-5,10-imine (ADCI) with its structural analogs dizocilpine (MK-801) and carbamazepine on ethanol withdrawal seizures. J Pharmacol Exp Ther 260: 1017-1022.

Gulya K, Grant KA, Valverius P, Hoffman PL, Tabakoff B (1991). Brain regional specificity and time-course of changes in the NMDA receptor-ionophore complex during ethanol withdrawal. Brain Res 547: 129-134.

Hedlund JL, Vieweg BW (1980). The Brief Psychiatric Rating Scale (BPRS): a comprehensive review. Journal of Operational Psychiatry 11: 48-64.

Hoffman PL, Rabe CS, Grant KA, Valverius P, Hudspith M, Tabakoff B (1990). Ethanol and the NMDA receptor. Alcohol 7: 229-231.

Hu XJ, Follesa P, Ticku MK (1996). Chronic ethanol treatment produces a selective upregulation of the NMDA receptor subunit gene expression in mammalian cultured cortical neurons. Brain Res Mol Brain Res 36: 211-218.

Hu XJ, Ticku MK (1995). Chronic ethanol treatment upregulates the NMDA receptor function and binding in mammalian cortical neurons. Brain Res Mol Brain Res 30: 347-356.

Hustveit O, Maurset A, Oye I (1995). Interaction of the chiral forms of ketamine with opioid, phencyclidine, sigma and muscarinic receptors. Pharmacol Toxicol 77: 355-359.

Kalluri HS, Mehta AK, Ticku MK (1998). Up-regulation of NMDA receptor subunits in rat brain following chronic ethanol treatment. Brain Res Mol Brain Res 58: 221-224.

Krupitsky EM, Burakov AM, Romanova TN, Grinenko NI, Grinenko AY, Fletcher J et al (2001). Attenuation of ketamine effects by nimodipine in recently detoxified ethanol dependent men: psychopharmacologic implications of the interaction of NMDA and L-type calcium channel antagonists. Neuropsychopharmacology 25: 936-947.

Krystal JH, D’Souza DC, Karper LP, Bennett A, Abi-Dargham A, Abi-Saab D et al (1999b). Interactive effects of subanesthetic ketamine and haloperidol. Psychopharmacology 145: 193-204. 
Krystal JH, Karper LP, Seibyl JP, Freeman GK, Delaney R, Bremner JD et al (1994). Subanesthetic effects of the noncompetitive NMDA antagonist, ketamine, in humans. Psychotomimetic, perceptual, cognitive, and neuroendocrine responses. Arch Gen Psychiatry 51: 199-214.

Krystal J, Petrakis I, Krasnicki S, Trevisan L, Boustros N, D’Souza DC (1999a). Altered responses to agonists of the strychnineinsensitive glycine NMDA coagonist (SIGLY) site in recently detoxified alcoholics. Alcoholism: Clin Exp Res 22: 94A.

Krystal JH, Petrakis IL, Webb E, Cooney NL, Karper LP, Namanworth S et al (1998a). Dose-related ethanol-like effects of the NMDA antagonist, ketamine, in recently detoxified alcoholics. Arch Gen Psychiatry 55: 354-360.

Krystal JH, Petrakis IL, Webb E, Cooney NL, Karper LP, Namanworth S et al (1998b). Dose-related ethanol-like effects of the NMDA antagonist, ketamine, in recently detoxified alcoholics. Arch Gen Psychiatry 55: 354-360.

Krystal JH, Tabakoff B (2002). Ethanol abuse, dependence, and withdrawal: neurobiology and clinical implications. In: Davis KL, Charney DS, Coyle JT, Nemeroff C (eds) Psychopharmacology: A Fifth Generation of Progress. Lippincott Williams and Wilkins: Philadelphia, PA. pp 1425-1443.

Kucera H, Francis WN (1967). Computational Analysis of Present Day American English. Brown University Press: Providence, Rhode Island.

Liang KY, Zeger SL (1986). Longitudinal data analysis using generalized linear models. Biometrika 13-22.

Malhotra AK, Pinals DA, Weingartner H, Sirocco K, Missar CD, Pickar D et al (1996). NMDA receptor function and human cognition: the effects of ketamine in healthy volunteers. Neuropsychopharmacology 14: 301-307.

Michaelis EK, Michaelis ML, Freed WJ, Foye J (1993). Glutamate receptor changes in brain synaptic membranes during chronic alcohol intake. Alcohol Alcoholism 2(Suppl): 377-381.

Miller ME, Davis CS, Landis JR (1993). The analysis of longitudinal polytomous data: generalized estimating equations and connections with weighted least squares. Biometrics 49: 1033-1044.

Moghaddam B, Adams B, Verma A, Daly D (1997). Activation of glutamatergic neurotransmission by ketamine: a novel step in the pathway from NMDA receptor blockade to dopaminergic and cognitive disruptions associated with the prefrontal cortex. $J$ Neurosci 17: 2921-2927.

Nestor PG, Faux SF, McCarley RW, Sands SF, Horvath TB, Peterson A (1991). Neuroleptics improve sustained attention in schizophrenia. A study using signal detection theory. Neuropsychopharmacology 4: 145-149.

Nestor PG, Faux SF, McCarley RW, Shenton ME, Sands SF (1990). Measurement of visual sustained attention in schizophrenia using signal detection analysis and a newly developed computerized CPT task. Schizophr Res 3: 329-332.

Newcomer JW, Farber NB, Jevtovic-Todorovic V, Selke G, Kelly Melson A, Hershey T et al (1999). Ketamine-induced NMDA receptor hypofunction as model of memory impairment and psychosis. Neuropsychopharmacology 20: 106-118.

Overall JE, Gorham DR (1962). The Brief Psychiatry Rating Scale. Psychol Rep 10: 799-812.

Oye I, Paulsen O, Maurset A (1992). Effects of ketamine on sensory perception: evidence for a role of $N$-methyl-D-aspartate receptors. J Pharmacol Exp Therap 260: 1209-1213.

Rafi-Tari S, Kalant H, Liu JF, Silver I, Wu PH (1996). Dizocilpine prevents the development of tolerance to ethanol-induced error on a circular maze test. Psychopharmacology 125: 23-32.

Schutz CG, Soyka M (2000). Dextromethorphan challenge in alcohol-dependent patients and controls. Arch Gen Psychiatry 57: 291-292.

Selzer ML (1971). The Michigan Alcoholism Screening Test: the quest for a new diagnostic instrument. Am J Psychiatry 127: $1653-1658$.

Snell LD, Nunley KR, Lickteig RL, Browning MD, Tabakoff B, Hoffman PL (1996). Regional and subunit specific changes in NMDA receptor mRNA and immunoreactivity in mouse brain following chronic ethanol ingestion. Brain Res. Mol Brain Res 40: 71-78.

Snell LD, Tabakoff B, Hoffman PL (1993). Radioligand binding to the $N$-methyl-D-aspartate receptor/ionophore complex: alterations by ethanol in vitro and by chronic in vivo ethanol ingestion. Brain Res 602: 91-98.

Spitzer RL, Williams JBW, Gibbon M, First MB (1990). Structured Clinical Interview for DSM-III-R-Non-Patient Edition (SCID-NP, Version 1.0 with Supplement for DSM-IV). American Psychiatric Press: Washington, DC.

Spitzer RL, Williams JB, Gibbon M, First MB (1992). The Structured Clinical Interview for DSM-III-R (SCID). I: history, rationale, and description. Arch Gen Psychiatry 49: 624-629.

Thomas MP, Morrisett RA (2000). Dynamics of NMDAR-mediated neurotoxicity during chronic ethanol exposure and withdrawal. Neuropharmacology 39: 218-226.

Trevisan L, Fitzgerald LW, Brose N, Gasic GP, Heinemann SF, Duman RS et al (1994). Chronic ingestion of ethanol upregulates NMDAR1 receptor subunit immunoreactivity in rat hippocampus. J Neurochem 62: 1635-1638.

Tsai G, Coyle JT (1998). The role of glutamatergic neurotransmission in the pathophysiology of alcoholism. Ann Rev Med 49: 173-184.

Tsai GE, Ragan P, Chang R, Chen S, Linnoila VM, Coyle JT (1998). Increased glutamatergic neurotransmission and oxidative stress after alcohol withdrawal. Am J Psychiatry 155: 726-732.

Vollenweider FX, Leenders KL, Oye I, Hell D, Angst J (1997). Differential psychopathology and patterns of cerebral glucose utilisation produced by $(S)$ - and $(R)$-ketamine in healthy volunteers using positron emission tomography (PET). Eur Neuropsychopharmacol 7: 25-38.

von Knorring AL, Bohman M, von Knorring L, Oreland L (1985). Platelet MAO activity as a biological marker in subgroups of alcoholism. Acta Psychiatr Scand 72: 51-58. 